\title{
LOS MORISCOS ARAGONESES: UNA DEFINICIÓN MÁS ALLÁ DE LA RELIGIÓN Y LA POLÍTICA
}

Gregorio Colás Latorre*

Hace ya tiempo Fernand Braudel, al tratar el tema de los moriscos en $E l$ Mediterráneo y el mundo mediterráneo en la época de Felipe $I^{1}$, afirmaba: "es cierto que Granada y Valencia, las dos vertientes de España (aragonesa la una, la otra castellana) no se hicieron «cristianas» (o, como se diría después, moriscas) en las mismas condiciones ni en la misma atmósfera. Y ello distingue, por lo menos, dos problemas moriscos". Y continúa, "pero, mirada la cosa un poco más cerca, encontramos otras distinciones y otras zonas, según que los moriscos abunden más o menos y se hallen más o menos encuadrados en la civilización de los vencedores y engarzados en ellas desde un tiempo más o menos largo" ${ }^{\prime 2}$. De esta manera transcribía en grandes trazos la diversa realidad social que presentaban los recientemente bautizados. En realidad no descubría nada nuevo. Se limitaba a sintetizar en unas escuetas líneas un hecho que todos hemos dado por supuesto y sabido. Su afirmación resultaba tan transparente que ha pasado prácticamente desapercibida, diluida en esa sensación de pertenecer al acervo común que acompaña siempre a toda cuestión calificada de evidente.

Es claro que no todos los moriscos habían llegado al bautismo en las mismas condiciones, ni estaban en la misma situación respecto a la civilización cristiana de la mayoría. Y no es menos cierto que la razón de esa diferenciación estaba en el tiempo de convivencia entre las dos comunidades, en su distribución geográfica y en su integración social. Sin embargo, a pesar de las palabras de Braudel, escritas por primera vez en 1949, de haber sido aceptadas unánimemente y de ser durante años uno de los temas más relevantes de la Historia Moderna de España, la minoría continúa percibiéndose

\footnotetext{
* Universidad de Zaragoza.

1. Braudel, F., El Mediterráneo y el mundo mediterráneo en la época de Felipe II, México, F.C.E., 1976 (edición en francés en 1966. Primera edición en francés en 1949).

2. Ibidem, T. II, p. 177.
} 
fundamentalmente a través de su peculiaridad cultural y religiosa de filiación totalmente musulmana, mientras sus relaciones con la mayoría cristiana se hallaban determinadas por sentimientos de enemistad y odio como convenía a fieles de credos distintos a los que se añadía el agravante de tratarse de vencedores y vencidos. Granadinos, valencianos y aragoneses todos eran, en definitiva, musulmanes y todos odiaban de la misma manera a los cristianos. El mismo Fernand Braudel, a pesar de haber hablado de la diversidad de la comunidad, explicó la expulsión, en aparente contradicción con lo que en principio daba a entender su discurso, por la imposibilidad de la sociedad cristiana de asimilar a la minoría que continuaba siendo mora como en vísperas de su bautismo ${ }^{3}$.

Ciertamente esta representación no es gratuita. Esta construida a partir del único elemento que, a priori, se entiende común a toda la comunidad: la fe y la cultura que proporciona su credo islámico. En contrapartida presenta una serie de graves inconvenientes. Afirma unívoca y universalmente la condición musulmana del colectivo, que invadiría todas sus actividades, a la vez que lo presenta como un todo aislado y enfrentado al cristiano. Es la imagen que ha transmitido la España oficial ${ }^{4}$, a través del Consejo de Estado y de la Inquisición, y, por tanto, fruto de los intereses políticos y religiosos, que de 1500 a 1600 acaudilló la monarquía hispana. Olvida que además de súbdito y fiel, el desterrado era un ente económico y social y, como tal, en relación con la organización socioeconómica y política de la sociedad cristiana que lo envuelve y en la que está inserto. Tampoco se ha valorado la incidencia, los efectos de este contacto sobre el mundo de las creencias y de la cultura. Finalmente, una parte de la historiografía ha sido víctima de un craso error. Ha otorgado a los papeles "estatales" e inquisitoriales una credibilidad que nunca debió conceder. Como toda documentación política, la del Consejo de Estado responde, ante todo, a unos determinados intereses, en este caso a los de la monarquía hispana del Quinientos. En ningún momento pretende ser testigo o dar testimonio de la realidad, de su tiempo. La Inquisición, por su parte, necesita herejes para sobrevivir además de conseguir las confesiones de sus víctimas, si es preciso, mediante tortura. Y siempre queda la duda, que nunca parece haberse planteado en el caso concreto de los moriscos, de la validez de un testimonio conseguido por la violencia, como ya en aquellos tiempos se tenía claro en Aragón. "Yo, escribía Lupercio Leonardo de Argensola en 1604, cierto creo que son tantas las mentiras que los hombres flacos publican en el tormento como las verdades; y al fin yo conozco hombres dignos de mil muertes que en el tormento con su perseverancia se libraron dellas; al fin se remite a la lengua del reo la sentencia que se le ha de dar:

3. Ibidem., T.II, p. 192.

4. Con matizaciones suscribo el epígrafe que Francisco MárqueZ VILlanueva dedica a las fuentes en «El problema historiográfico de los moriscos», El problema morisco (desde otras laderas), Madrid, Libertarias, 1991, pp. 166-171. 
los delicados o flacos dicen en el tormento lo que les dicta el dolor presente, sin memoria de la pena que, si confiesan, han de padecer, y confórmanse con el deseo del juez, que, añadiendo al dolor esperanzas y promesas (que es otro género de violencia), le persuade todo va encaminado a hacer justicia" ${ }^{\prime 5}$. Las carencias de la tesis que ha vertebrado una gran parte de la historiografía morisca hasta estos momentos no terminan aquí. Lo apuntado cumple simplemente el objetivo de poner en entredicho su valor mientras dejo para un futuro estudio tratar, esta vez en profundidad, toda la problemática que encierra la cuestión religiosa de los nuevos bautizados en un mundo religioso y creyente como el del siglo XVI.

Para el Consejo de Estado y el Santo Oficio toda la minoría era y vivía como moros. Había renegado del bautismo y conspiraba con los enemigos de la monarquía. Son las dos connotaciones que encierra el término morisco. De ahí su carácter negativo. Define a los antiguos mudéjares por su condición de renegados y rebeldes y afirma su fe y, por ende, su cultura musulmana. Por estas dos razones, por su falso cristianismo y por su traición, fueron expulsados. También por eso se aplica indistintamente a todo el colectivo con independencia de su geografía y es el único que se utiliza tras la expulsión cuando públicamente han sido acusados de musulmanes y de enemigos de la corona. La condición de criptomusulmanes, que tenían para la Inquisición, explicaría que en su documentación dominase el término morisco por encima de cualquier otro. Se evangeliza a los nuevos convertidos pero se desarma, se procesa o se encarcela a los moriscos. Las negativas referencias que acaba por encerrar el término transcederán el marco religioso y político, utilizándose, fuera del ámbito del Consejo de Estado y del Santo Oficio, para designar a los nuevos cristianos delincuentes. Así, en Aragón, se califican de moriscos a los recientemente bautizados o a sus descendientes autores de actos o acciones social o políticamente reprobables. De moros se trata a los traficantes, nuevos bautizados, en trigo y ganado que en la feria de Alcalá no respetan la "vieda". Y moros son, asimismo, los que en dicha feria del año 1576 resistieron violentamente (a pedradas) a los guardas del general $1^{6}$. También se llama moriscos a los nuevos cristianos que asesinaron en Alba (Castilla) a unos correligionarios suyos para robarles en torno a 1600. Lupercio Leonardo de Argensola en su Información de los sucesos del Reino de Aragón en los años de 1590 y 1591 titula el conflicto entre gentes de Jaca y Sallent y las de Codo: De las discordias y casos entre los montañeses y mo-

5. ARGENSOlA, Lupercio L., Información de los sucesos del reino de Aragón en los años de 1590 y 1591, en que se advierte los yerros de algunos autores escrita por..., Madrid, 1808, p. 67 (reedición facsimilar Zaragoza, Rolde, 1991. Introducción de Xavier Gil Pujol). Lupercio L. de Argensola escribió la obra en 1604 aunque se negó a publicarla ante las correcciones que le exigía introducir la censura. Permaneció inédita hasta 1808.

6. A(rchivo) D(iputación) Z(aragoza), Actos comunes 1576, Ms. 231, f. 128. 
riscos ${ }^{7}$. Referencias que ilustran bien el concepto peyorativo del término morisco que ya no sólo significaba al renegado de moros sino también al mal ciudadano.

Para el historiador las cosas no deben ser tan simples como ya señaló en su día Francisco Márquez Villanueva ${ }^{8}$. Si recurre a otros testimonios puede observar que la realidad de la minoría era mucho más compleja tanto respecto a sí misma como respecto a la mayoría. Parafraseando a Fernand Braudel, no había un solo problema sino varios. El morisco aragonés, objeto de este trabajo, tiene una personalidad diferenciada del granadino y valenciano. Frente a la pretendida indiferenciación del aparato del "Estado", la otra documentación lo presenta integrado en la sociedad y en el orden político aragonés y posiblemente más próximo a sus vecinos cristianos de lo que estaban sus "correligionarios" granadinos y valencianos.

Más allá de la Inquisición o del "Estado", cuando nos retiramos de la Monarquía Universal Católica al ámbito de Aragón, allí donde entran en juego otros aspectos y valores además de los religiosos y políticos, la consideración y denominación de los recientemente bautizados y de sus descendientes son bien distintas. En los contratos de índole diversa que se realizan ante notario, una vez superada la generación del bautismo que generalmente recuerda el nombre musulmán del nuevo cristiano, la condición religiosa de los intervinientes está limitada a la mínima expresión. En las capitulaciones matrimoniales, en los testamentos, en las procuras, comandas, etc. el descendiente de mudéjares se encuentra mayoritariamente con su nombre y apellidos como el cristiano viejo sin que ningún apelativo recuerde su peculiar estado. El término morisco no aparece nunca ${ }^{9}$. Y el de nuevo cristiano, que tiene una connotación bien distinta, sólo ocasionalmente. Cuando así ocurre, se tiene la sensación de que únicamente por expreso deseo de la parte se recoge su condición. No se trata de un requisito impuesto por la sociedad cristiana, lo que constituye un hecho para la reflexión. Sin embargo, lo más digno de reseñar es que en multitud de operaciones y de actos ningún epíteto identifica al nuevo bautizado como tal. El historiador sólo tiene sus apellidos que en muchas ocasiones no le sirven de mucho porque son totalmente cristianos.

Relegado mayoritariamente el término morisco a los dominios del Santo Tribunal y del Consejo de Estado, las expresiones dominantes, utilizadas para designar a los hijos de los antiguos musulmanes, son las de nuevo convertido, nuevo cristiano o nuevo bautizado y de estas tres posiblemente sea la de nuevo cristiano la más usada. Con ella se fija su condición de re-

7. ARGENSOLA, L.L., op. cit., p. 61 .

8. MÁrQUez VILLANUEVA, FCo., «La criptohistoria morisca (los otros conversos)», El problema morisco... op. cit., pp. 13-44. Id., «El problema historiográfico....», pp. 98-195.

9. Debe entenderse que el autor no lo ha encontrado nunca. 
ciente bautizado y, por tanto, en proceso de formación en la verdadera doctrina y de integración en la sociedad cristiana. Sirve también de identificación, cuando es necesario, frente a los cristianos viejos. Por eso es inseparable del mundo concejil. Como es de todos sabido durante la Edad Media las tres comunidades que habitaban las tierras hispanas estaban organizadas a nivel municipal en aljamas y concejos. Tras la expulsión de los judíos quedaron la aljama mora y el concejo cristiano. Con el decreto de bautismo de 1525 la aljama desapareció o se transformó en concejo, como se verá más adelante. Desde entonces la expresión nuevos cristianos designaba al concejo recientemente constituido al mismo tiempo que lo acotaba y definía frente al de los viejos. Nuevos cristianos o nueva cristiandad designará la pertenencia a la comunidad de los recientemente bautizados.

En la documentación señorial, que durante los últimos tiempos he trabajado con el propósito de estudiar en profundidad a los moriscos aragoneses, los descendientes de los antiguos mudéjares reciben sistemáticamente el nombre de nuevos cristianos cuya representación ante el señor, los otros concejos, las autoridades del rey o del reino la tiene el concejo de los nuevos cristianos. Los cabreos, los censos, las concordias, las capitulaciones, etc. etc., las realiza en nombre de la minoría, asentada en ocasiones en un barrio del lugar, el concejo de los nuevos cristianos. Sólo después de 1610, en perfecta consonancia con lo expuesto más arriba la expresión cristianos nuevos es sustituida por la de moriscos. Los que eran nuevos bautizados hasta el 28 de mayo de 1610 se convierten el 29 (día en que se leyó el bando de expulsión en Zaragoza) en moriscos, término que irremisiblemente designará a perpetuidad a la minoría. Las cartas de población se otorgarán para llenar el hueco dejado por los moriscos, que en la documentación de los respectivos señoríos anterior al destierro son nuevos cristianos. Los panegiristas hablarán de expulsión de los moriscos.

Como he dicho, morisco es el término que define a la comunidad como musulmana, en su religión y en su cultura, y como tal enemiga de la cristiana. Sin embargo, a pesar de lo que machaconamente se ha insistido, creo que es legítimo preguntarse hasta dónde eran realmente musulmanes los moriscos aragoneses y hasta dónde llegaba el antagonismo entre las dos comunidades. Para la Inquisición, para el Consejo de Estado y para el gobierno de Felipe III lo eran. También para quienes escribieron y alabaron la expulsión. Desde el siglo XVII la condición musulmana y el odio entre las dos comunidades ha sido una especie de axioma sistemáticamente defendido. Convicción tan profunda que hechos que admitían otras lecturas, mucho más fructíferas y ajustadas a la realidad, han sido utilizados para reforzar la vieja acusación de renegados por la que fueron expulsados. Entre ese florilegio de hechos que permiten otras lecturas, tal vez merezca destacarse las representaciones teatrales que se hicieron en distintos pueblos moriscos en 1574 y la interpretación que se les ha dado. Se trata de dos piezas en castella- 
no, Auto de la destruyción de Troya y Comedia pastoril de Torcato. En palabras de Francisco Ynduráin, "obras de la más remontada calidad literaria en la temática de nuestra cultura: guerra de Troya y comedia pastoril no rústica" ${ }^{10}$. Su autor fue Francisco de Arellano, "abitante en la villa de Anbel y natural de la villa de Agreda"11. Las obras fueron representadas al menos en Borja y Maleján y evidentemente por moriscos en vísperas de la Pascua de Navidad.

En principio la representación pasó desapercibida. Era una más de las actividades festivas que tenían lugar durante el invierno. Fue precisamente a raíz de la carta, que envió la Inquisición a los comisarios y familiares, exigiéndoles que informasen "si endespués de la pérdida de la Goleta se mostró muy largamente en los nuebos combertidos algún regozijo o fiestas"12, cuando el comisario Marcos Valforga de Borja concluyó que las comedias se habían hecho para festejar la caída de la Goleta ocurrida cinco meses antes. Incluso encontró una justificación a su sospecha "se a bisto largamente por aber echo una comedia de la destruición de Troya en la qual contenía ciertas palabras las quales ban señaladas en el mesmo acto de la representación que ba con esto ${ }^{\prime 13}$. Lógicamente las obras fueron secuestradas y enviadas a la Inquisición. La actuación del tal Marcos no fue excepcional. Por el contrario se mueve en un contexto de denuncias generalizadas. Cada comisario respondió a la advertencia inquisitorial de la misma manera y cuantas fiestas hicieron los moriscos a partir de agosto fueron calificadas de celebraciones por la toma de la Goleta.

La interpretación del comisario de Borja es sin duda una de las posibles pero no deja de parecer sospechosamente tendenciosa y, en consecuencia, poco o nada creíble. La distancia entre el hecho de armas y los festejos, el momento de la denuncia y la naturaleza de las celebraciones restan verosimilitud a la acusación que está inducida por la Inquisición y parece más una justificación del cargo y una forma de congraciarse o adular al Tribunal que una fría explicación de lo sucedido. Y más si se tiene en cuenta que "las dos obras forman parte del proceso, como piezas de cargo... Lo que no veo es que haya «ciertas palabras» en el auto, que puedan servir de indicio siquiera para acusar de que la obra alude a la caida de La Goleta"14. Frente a la denuncia precipitada por la Inquisición, y sin entrar en el ánimo que invadía a los moriscos ante los hechos de armas de los turcos, se podía entender mejor

10. YNDURAIN, FCo., Los moriscos y el teatro en Aragón. Auto de la destruyción de Troya y Comedia pastoril de Torcato, Zaragoza, Institución Fernando el Católico, 1986, p. 7.

11. Ibidem, p. 9.

12. Ibidem, p. 162.

13. Ibidem.

14. Ibídem, p. 9. El mismo autor alude a que "acaso en la representación, palabras que leídas parecen inocuas pudieran haber tenido segunda intención". Pero no sé si entonces no resulta más complicado entender el secuestro. 
que detrás de las comedias no hay nada más que una de tantas veladas que tenían lugar durante el invierno para distraer las aburridas horas de ocio que dejaba el trabajo del campo. Pero sobre todo merece destacarse, por las obras de teatro representadas, que, cualquiera que fuera su convicción religiosa, el nuevo cristiano conocía bien la cultura occidental y gustaba de la misma. Culturalmente, al menos, estaba fuertemente integrado en el mundo cristiano. "Haré notar [escribe Francisco Ynduráin] que el teatro llegaba hasta lugares apartados y que los moriscos lo representaban"15. Y este hecho me parece mucho más importante que la pretendida celebración inquisitorial de caída de La Goleta.

Unos años antes, otro hecho bélico había sido interpretado de la misma manera. La toma de la ciudadela de Menorca por la escuadra turca en 1558 y el potencial peligro que corrió Barcelona despertaron la susceptibilidad inquisitorial hacia los nuevos cristianos. Y así se entendió que, cuantas fiestas se hicieron en algunos lugares del ducado de Hijar, celebraban la inminente llegada de la escuadra turca a Barcelona. Festejos que el Santo Oficio describía unos años después a Felipe II en estos términos: "se vistieron como moros y hizieron juegos de cañas, corrieron toros y otros muchos regozijos $^{\prime \prime 16}$. Los historiadores ${ }^{17}$, por su parte, han aceptado la opinión inquisitorial y la han sumado al rosario de pruebas que aducen para demostrar la condición morisca de la minoría y su consideración de quinta columna del turco y de los enemigos de la monarquía católica. Sin embargo, pasando por alto otro tipo de consideraciones, la acusación de la Inquisición no sé si casa bien con el tipo de fiestas que denuncia. Es posible que los conversos celebrasen los éxitos de la armada turca pero llama la atención que lo hicieran con fiestas totalmente cristianas: el juego de cañas y la corrida de toros. Y esto es, en mi opinión, como he apuntado anteriormente, lo realmente importante a la hora de estudiar su integración. De la misma manera me parece motivo de reflexión el que hechos que la Inquisición denuncia como pruebas de la traición morisca, tengan componentes de inconfundible cultura cristiana.

Teatro, juego de cañas, corrida de toros..., diversiones que denuncian una fuerte penetración de la civilización dominante que viene además avalada por otros hechos todavía más relevantes. Según Cervantes, a los moriscos de Aragón se les llamaba en Argel "tagarinos" término que en España designaba a "los moriscos antiguos criados entre christianos viejos, en lugares de Castilla y Aragón, los quales saben igualmente nuestra lengua y la suya, de

15. Ibidem, p. 8.

16. AHN. Inquisición, Libro 988 , f. 80 .

17. REGLÁ, J., "La cuestión morisca y la coyuntura internacional en tiempos de Felipe II», Estudios sobre los moriscos, Barcelona, Ariel, 1974, p. 201. También CARRAsCo URGOITI, $\mathrm{M}^{\mathrm{a}}$. S., El problema morisco en Aragón al comienzo del reinado de Felipe II (Estudio y apéndices documentales. Estudios de hispanófila 11), Madrid, Castalia, 1969, p. 49. 
modo que apenas se pueden distinguir ni conocer, salvo por la orden que con ellos se tiene de que vivan en ciertos barrios" ${ }^{\prime 18}$. Otros testimonios confirman también esta integración. Se ajusta bien a mi propósito el de Lupercio Leonardo de Argensola quien en 1604 escribía sobre esta cuestión: "hai en Aragón, como en otros muchos reinos de España, muchos moriscos, aunque en hábito y en lengua no se diferencian de los otros hombres" ${ }^{19}$. Los mismos procesos inquisitoriales testifican que los moriscos aragoneses a diferencia de los valencianos hablan el aragonés o el castellano. La élite no sólo lo habla, también lo escribe.

Si el islam, además de una religión, es una lengua y una cultura habrá que convenir que, al menos, entre la minoría de nuevos convertidos aragoneses, cualquiera que sea su vivencia de la fe mahometana, se ha producido un fuerte desajuste entre lo que impone la religión y sus manifestaciones culturales y entre lo que se ha dicho respecto a la minoría y lo que denuncian estas pruebas. Desajustes que deberían llevar a revisar algunas de las opiniones que se han defendido en el pasado.

Nada diré respecto de su religión. Me limitaré a plantear si se puede calificar de científica la actitud que se ha adoptado frente a las fuentes que han servido para defender la condición islámica de los nuevos bautizados. Mi propósito no es negar tal condición. Pretendo sólo llamar la atención sobre la credibilidad de la documentación utilizada a la hora de definir la religión y religiosidad de los nuevos convertidos y si permite conclusiones universales sobre la minoría. De hecho, en otras esferas de la vida social de los hombres,

18. Cfr. Carrasco UrgotTi, $M^{a}$ S., op. cit., p. 39.

19. ARgensola Lupercio L., op. cit., p. 61. La cita no termina aquí. Pero de lo que dice a continuación una parte, la referida al armamento de los moriscos, es falsa. Escribe que "ni entonces se diferenciaban en el uso de todas armas: agora no pueden traer ni aún cuchillos con punto, por prohibición del Santo Oficio y entonces traían arcabuces". El texto se refiere a 1592 pero ya antes, desde 1558-1559 los nuevos cristianos tenían prohibido por la Inquisición llevar armas mientras el primer desarme oficial se decretó en 1575. También es conveniente explicar el resto de las afirmaciones de Lupercio que responde bien a la doctrina oficial pero que para valorarlo en su justa medida es conveniente integrarlo en su contexto. Continúa diciendo "Generalmente discordan de todos los cristianos viejos que, como sospechan que estos fingen seguir la religión de Cristo, son comúnmente aborrecidos, y todas sus acciones sospechosas". Palabras que pretenden justificar el conflicto con los montañeses y la rebelión de 1591. María Soledad CARRASCO URGOITI, en op. cit., p. 39, dice que "el nuevo convertido no se destinguía, nos dice Argensola, en hábito y en lengua de los demás hombres": y atribuye la cita a Argensola en sus Anotaciones a Cabrera de Córdoba, en p. 46 nota 6. Leídas con detenimiento tales Anotaciones no he encontrado dicha referencia. Es muy posible que la memoria le gastara una mala pasada a la profesora Carrasco Urgoiti. Quien se refiere al hábito y lengua de los nuevos convertidos es Lupercio Leonardo de Argensola en su obra citada, pero Lupercio no escribió las Anotaciones a Cabrera de Cordoba sino su hermano Bartolomé L. de Argensola, quien a su vez sí menciona algunos aspectos, muy positivos por cierto sobre los moriscos, pero no dice nada respecto a su habla y vestimenta. Las notas de Bartolomé Leonardo de Argensola a Cabrera de Córdoba en CABRERA DE CORDOBA, L., Felipe Segundo, rey de España, Madrid, 1877, T. III, pp. 520-611. 
las confesiones obtenidas por la fuerza, con tortura, tendrían una credibilidad limitada. También se ha sabido distinguir entre el mundo de los principios y la realidad, entre la teoría y la práctica, entre el catecismo, el tratado teológico, la obra ascética o mística y lo que es la vida religiosa del pueblo. Pero ise ha tenido tal actitud ante los moriscos y las fuentes que hablan de su fe y de su religiosidad?

La otra tesis que ha vertebrado una parte importante de la historiografía ha sido la del odio entre ambas comunidades. Ha sido tal su presencia en los últimos tiempos que se ha considerado el antagonismo como el sentimiento que animaba las relaciones entre las dos partes. Sin embargo, cuando descendemos de las alturas de la política y de la religión a la vida cotidiana de la comunidad aldeana o a los materialistas intercambios económicos, el antagonismo se disuelve en unas relaciones que no difieren sustancialmente de las que mantenían los cristianos en su comunidad y los nuevos bautizados en la suya.

Es verdad que durante la centuria se encuentran conflictos que podrían argüirse en contra de la tesis aquí defendida. Sin embargo, se puede replicar que por su número más que contravenir confirman la norma general de una buena convivencia. Además, salvo puntuales excepciones, ni están vinculados al grupo ni difieren sustancialmente de los habidos entre los propios cristianos o entre los mismos moriscos. Los altercados dentro de la sociedad cristiana en el Aragón del siglo XVI son tantos y tan graves y la delincuencia tan acusada que el rechazo mutuo no puede ser el argumento universal que explique la delincuencia entre moros y cristianos. Precisamente esa tensión social y política, estudiada parcialmente ${ }^{20}$, explica mejor que cualquier otro argumento algunas de las medidas tomadas contra la minoría, que incluso en un determinado momento llega a ser su víctima propiciatoria. Es lo que ocurre en 1587 entre los montañeses de Jaca y Sallent y los vecinos de $\mathrm{Codo}^{21}$. El conflicto podría ser calificado de confesional. Sin embargo la cantidad de factores ajenos a los bandos, que intervienen, descarta su naturaleza religiosa como única y fundamental explicación. El litigio, muy grave, es ante todo un enfrentamiento entre ganaderos y labradores que, ante la inhibición de unos y permisividad de otros, termina por canalizar las graves tensiones sociales de la zona y políticas del momento.

Los delitos, incluso los enfrentamientos, no deben ocultar que son compañeros inseparables de unas relaciones permanentes entre ambas comunidades que muestran una tendencia sostenida a la aceptación mutua, al respeto e incluso a la integración allí donde más claramente podía manifestarse:

20. Colás Latorre, G. y Salas Ausens, J. A., Aragón en el siglo XVI: alteraciones sociales y conflictos políticos, Zaragoza, Departamento de Historia Moderna, 1982.

21. Este conflicto está por estudiar en profundidad. Una buena aproximación al mismo en Colás Latorre, G. y Salas Ausens, J. A., op. cit., pp. 595-610. 
en la comunidad rural. Las pruebas de esta tendencia afloran inmediatamente al decreto de bautismo de 1525. El nuevo cristiano pretende ser igual que el viejo. Aspiración que se concretaba en un primer objetivo: pagar lo mismo. La primera percepción que, sin duda, tenía el recién bautizado de la diferencia que le separaba de sus nuevos correligionarios era precisamente económica. En los lugares de señorío los viejos pagaban mucho menos que los nuevos. De ahí que eliminar este, para ellos, importante elemento de diferenciación, fuera una de sus primeras reivindicaciones. Con parecida intensidad pretendía acabar con otro factor de distinción: la organización municipal. Con el bautismo la aljama desaparecía y, por tanto, debía formar un solo pueblo con los viejos y estar bajo la dirección de un mismo concejo. Esta era posiblemente la aspiración de los sectores más acomodados de los recientemente bautizados. La misma demanda apareció entre los cristianos viejos.

Hace años, en 1979, escribía que la dualidad municipal, concejo y aljama, de las poblaciones con las dos comunidades se perpetuó por el egoísmo de los señores tras el decreto del bautismo ${ }^{22}$. El concejo del lugar continuó representando a los cristianos mientras la aljama fue sustituida por el concejo de los cristianos nuevos ${ }^{23}$ que defendía los intereses de los recientemente bautizados. También señalaba que en Caspe, la bailía entonces estudiada, había habido, según denunciaban los actos notariales, un movimiento, que debió ser importante, protagonizado por gentes de ambas comunidades para formar un solo concejo ${ }^{24}$. Movimiento que fue abortado por el señor, la orden de san Juan de Jerusalén a la que pertenecía la ciudad caspolina, entonces villa. Ahora, después de las investigaciones realizadas puedo afirmar que las soluciones fueron más complejas y el movimiento de integración más amplio y de más largo alcance. En principio hay que empezar por distinguir entre realengo y señorío. En los lugares del rey la aljama desapareció y con ella los nuevos bautizados quedaron integrados dentro del resto de la población bajo el gobierno y dirección del concejo cristiano mientras su élite dirigente pasaba a estar insaculada en las bolsas de los oficios del concejo. Bien es cierto que, aunque el proceso de esta integración así como los distintos cargos a los que podían acceder está por estudiar, el colectivo parece que fue aceptado con todas sus consecuencias. A partir de 1526 ingresos y gastos de la aljama se integran en la administración del viejo concejo mientras los nuevos vecinos desempeñan dintintos cargos, asisten a los concejos generales y forman parte del colectivo vecinal.

En el caso del señorío la respuesta es más compleja. Donde sólo había nuevos cristianos no hubo ningún problema. La aljama se transformó en

22. ColÁs LATORRE, G., La bailía de Caspe en los siglos XVI y XVII, Zaragoza, Institución Fernando el Católico, 1979, pp. 26-31.

23. Ibídem, p. 27, nota 57.

24. Ibidem, p. 29. 
concejo al mismo tiempo que desaparecían los oficios específicamente musulmanes. Empezó a llamarse concejo de Muel, Alborge, Maleján, etc. A partir de 1525 no he encontrado ni una sola vez la expresión aljama para referirse a una determinada población que antes la hubiera tenido. Ni siquiera allí donde la población era toda de nuevos bautizados, el término concejo se ha hecho acompañar del determinante nuevos convertidos o nuevos cristianos. Cuando el lugar estaba poblado por las dos comunidades, la solución por excelencia, cuando las dos comunidades tenían suficiente entidad, fue la perpetuación de la dualidad municipal. Continuó el concejo mientras la aljama fue sustituida por el concejo de los cristianos nuevos pero hubo excepciones. En Bulbuente, villa próxima a Borja, en el Somontano del Moncayo, el decreto de bautismo supuso la desaparición de la aljama y el establecimiento de un solo concejo, regido por viejos y nuevos cristianos, para una sola población. No debió ser el único caso.

El dualismo concegil, allí donde se mantuvo, fue impuesto, en contra de las tendencias de la comunidad, por los señores. Sin embargo tal división, en contra de lo que pueda opinarse, no parece estar ligada a la condición de nuevos bautizados sino al peso que tenía su contribución en la definición de la renta señorial, a los intereses del señor y al mantenimiento de su prestigio. El nuevo cristiano se mantiene separado del viejo no por su condición religiosa sino porque paga unas rentas más elevadas y además conviene mantener divididos a los vasallos. La actitud señorial parece fácilmente justificable. Sin encontrar otros ingresos alternativos, y la monarquía no se los dio, los señores no podían reducir a sus vasallos las rentas que pagaban por el trabajo de sus tierras ni renunciar a los seculares derechos que tenían sobre la aljama. Tal vez durante el siglo XVI los nuevos cristianos achacasen a su condición de descendientes de moros sus pesadas cargas sin embargo no era así. La explicación no está en la ascendencia o en la religión sino en la propiedad de la explotación ${ }^{25}$. Es posible, que los primeros mudéjares trabajasen las tierras del señor por ser musulmanes pero en 1526 no se podía argumentar semejante principio para eludir la detracción señorial. Sin olvidar que la condición de vencidos y musulmanes pudo estar siempre en el subconsciente de las relaciones entre las partes, a tenor de cuanto ocurre en el señorío y del trato dispensado a los nuevos pobladores tras la expulsión, la detracción que sufre la familia campesina morisca (me refiero lógicamente a la que mediatiza su potencial económico gravemente) no precisa para su explicación recurrir a factores ajenos a los estrictamente económicos. Más aún sólo desde la economía se encuentra una justificación coherente con lo que es el discurso de la exacción en los señoríos aragoneses. Los moriscos pagaban más que los

25. Vid. sobre el tema de la renta señorial COLÁs LATORRE, G. «La historiografía sobre el señorío tardofeudal» en Sarasa, E. y Serrano, E., Señorio y feudalismo en la Peninsula Ibérica, ss. XIIXIX, Zaragoza, Institución Fernando el Católico, 1993, T. I, pp. 51-105. 
cristianos no porque fueran descendientes de los musulmanes sino porque trabajaban tierras pertenecientes al señor.

Sin embargo, a pesar de que se pueda articular una explicación al margen de la religión y la cultura, la detracción, que soportaba, diferenciaba también a la minoría de la mayoría cristiana y al coincidir con rasgos específicos religiosos y culturales era fácil atribuir aquélla a éstos. La peripecia histórica se interponía en la integración. La exacción, la tributación define al cristiano nuevo frente al viejo pero no es la religión o la cultura la causante de esa diferenciación, aunque el recientemente bautizado no lo sepa, sino la historia. Cuando, después de la expulsión, llega el momento de repoblar los lugares y tierras abandonadas por los moriscos, los señores entregan casas y tierras a los nuevos pobladores en mejores condiciones que las tenían los expulsados; pero eran mucho más pesadas que las soportadas por los viejos pobladores Esta mejora no es producto de la religión sino del mercado de trabajo. Incluso el comportamiento señorial llega a recordar al de 1526 en la política concegil. En ciertos lugares los nuevos repobladores son constituidos en principio como concejo separado e independiente del viejo concejo de la villa.

Los señores mantienen separadas ambas comunidades, pero sin que les empuje otro motivo que la defensa de sus intereses. El pueblo, por su parte, los sectores dirigentes del mismo, mantienen vivas las tendencias a la integración aparecidas en 1526. Lo que, por otra parte, debe entenderse como una prueba fehaciente de las escasas diferencias externas que debía mostrar una comunidad respecto a la otra. La existencia de esa permanente aceptación mutua se puso de manifiesto entre otros lugares en los del señorío del monasterio de Rueda. En 1567 los concejos de cristianos nuevos y viejos de Escatrón (villa aguas abajo del Ebro) y el de Codo (pequeña población vecina de Belchite), que era de nuevos, acordaron salir en defensa del monasterio que, acosado por las deudas, no encontraba otro medio de superar su quiebra económica que la venta de sus lugares a señor laico. Para evitar su enajenación, los tres hicieron frente solidariamente a las deudas que tenía el monasterio. El acta notarial, sumamente interesante, ilustra bien algunas de las cuestiones aquí tratadas. Por eso me atrevo a recoger en estas páginas un amplio extracto de la "Capitulación y concordia hecha entre los jurados, Concejo y universsidat y singulares personas de christianos viejos de la villa d'Escatron y los jurados, concejo y universsidat y singulares personas de christianos nuebos de la dicha villa, y los jurados concejo y universsidat y singulares personas vezinos y habitadores del lugar de Codo de la parte otra" 26 .

La concordia se hacía, según las partes por las siguientes razones: "Et primeramente: Attendido y considerado que a noticia de los dichos concejos

26. Cfr. SAN VICENTE, A., Colección de fuentes de derecho aragonés del Bajo Renacimiento, Zaragoza, Secretariado de publicaciones de la Universidad, 1970, p. 361. 
y universidades... ha llegado que el muy ilustre Rey Gomez de Silva principe de Evoli ha tractado y tracta con los muy reverendos abad, monjes y convento de Nuestra Senyora de Rueda de comprar la dicha villa d'Escatron y lugares de Lagata (nuevos convertidos) Codo, Sanctper del Salz y otros bienes y cosas del dicho monesterio con pretensión que el dicho monesterio está en muy grande necesidat y ruyna por estar cargado de deudas; et attendido que si dicha vendición se effectuasse seria en total ruyna del dicho monesterio y perdición de los dichos vasallos pues de personas que son libertadas y gozan de los fueros, usos y costumbres del presente reyno de Aragón, passando en el dicho Ruy Gomez serían perpetuamente esclabos pues los señores seculares de vasallos en el presente reyno de Aragón les es permitido bien y mal tractar sus vassallos, matarlos de hambre y sed y quitarles sus haziendas sin que dello pueda haber recurso ni apellación alguna al rey nuestro señor ni otra persona alguna; y attendido que en Aragon los vassallos valen mucho y siempre se augmentan las rentas por ellos y si los dichos lugares se ajenassen y al dicho monesterio por ellos se diessen dineros y censales por el tiempo todos se consumirian y consumidos quedaria el dicho monesterio perdido, lo que no acaescera tubiendose los lugares como siempre los ha tenido; por tanto y por otras justas causas y razones nuestros animos a lo infrascripto hazer mobientes y por remediar las cosas del dicho monesterio y necessidades de aquel et porque siempre se este como ha estado celebrandose los divinos officios con muy grande debocion y no dar lugar a que dichos villa y lugares sean separados de la casa y monesterio...como vasallos fidelissimos del dicho monesterio para las cosas infrascriptas hazemos entre nosotros dichos tres Concejos, el uno de los jurados Concejo y universsidat de christianos viejos de la dicha villa d'Escatron y el otro de los jurados, Concejo y universsidat y singulares personas de christianos nuebos de la dicha villa, y el otro de los jurados, Concejo y universsidat y singulares personas del dicho lugar de Codo los quales dichos tres Concejos por pacto especial entre nosotros inido y concordado prometemos y nos obligamos los unos a los otros et viceversa de contribuyr y realmente pagar cada uno de dichos tres Concejos por yguales partes todas y qualesquiere sumas siquiere cantidades de dineros y otras qualesquiere cosas que se hubieren de pagar a los muy reverendos abbad, monjes y convento del dicho monesterio de Nuestra Señora de Rueda et por ellos ad aquellas personas o personas, cuerpos, collegios y universidades que se hubieren de pagar..."27. Cristianos viejos y nuevos juntos para mantener su condición de vasallos de iglesia que era privilegiada respecto a la que tenían los hombres de señorío laico. Hasta tal punto era privilegiada que, como el resto de los vasallos de iglesia, no importaba fueran estos cristianos viejos o nuevos, estaban equiparados jurídicamente, se entiende en el disfrute de los derechos y recursos del Justicia de Aragón, a los hombres libres, como recoge el texto citado.

27. Ibídem, p. 362 . 
Iguales en sus derechos individuales, las buenas relaciones existentes entre ambas comunidades dentro de la villa de Escatrón quedaban confirmadas en la fusión de los dos concejos que tuvo lugar en 1583. Como ocurría con el monasterio, tampoco la hacienda municipal de los cristianos nuevos gozaba de buena salud. En realidad estaba en bancarrota y los expertos no encontrarán otra solución que la disolución del concejo de los nuevos en el de los viejos. Aceptada la propuesta por cada colectivo, fue aprobada a continuación por el abad, monjes y capítulo del monasterio de nuestra señora de Rueda $^{28}$. Era el 12 de diciembre de 1583. Cuanto sucede en Escatrón, y esto es lo que realmente me interesa señalar, no parece estar presidido por el odio, el antagonismo o la separación visceral de las dos comunidades. Responde más bien y se explica mejor, si se acude a otras razones distintas a los hasta ahora masivamente manejados para explicar las relaciones entre las dos comunidades.

La tesis del antagonismo lleva a pensar, incluso presupone, que cada una de las partes vivía encerrada en sí misma y de espaldas a la otra a la que rechazaba por principio. Esto sería especialmente acusado en el caso del morisco quien se negaría a aceptar todo lo cristiano, no sólo la religión sino también la sociedad y el ordenamiento político y con él los derechos que le garantizaba. Rechazo al que respondería la mayoría cristiana con la misma moneda. Abandonado a su suerte, el morisco sería fácil presa de todos los desaprensivos. Especialmente de los señores. Sin embargo, la realidad se muestra distinta. El cristiano nuevo, como hacía el viejo, aceptó y buscó la protección que le brindaba el régimen político aragonés mientras las instituciones aragonesas lo protegieron sin reparos como hacían con cualquier aragonés. Y lo hicieron por una sencilla razón: para la Diputación y el Justicia el morisco era un aragonés más y como tal tenía los mismos derechos que el resto de la población. Esta valoración aparece claramente en el texto que se recoge a continuación y no es evidentemente la única prueba que se puede aducir. El 20 de septiembre de 1590, Codo, el pequeño concejo de nuevos convertidos, citado más arriba, otorgaba poder a Juan de Villafranca y Martín de Lanuza, notarios causídicos de Zaragoza para que pudieran "parezer y parezcan en la corte del señor Justicia de Aragón y ante qualesquiere señores, lugarteniente o lugartenientes suyos, en juizio y público consistorio y fuera de la celebración del, según y como para lo infrascripto más convenga y en qualquiere processos de firmas ${ }^{29}$ inhibitiones assí privilegiadas, ca-

28. AHN, Clero, leg. $8531-8532, n^{\circ} 19$, leg 2 2, s.f.

29. No es fácil sintetizar en unas escuetas líneas qué era la Firma. Para el lector lego en historia de Aragón posiblemente le sea suficiente con saber que se trataba de uno de los recursos jurídicos, el otro era la Manifestación que expedidos por el Justicia garantizaban los derechos "constitucionales" de los aragoneses. En este caso concreto se trata de las Firmas que emitidas por el Justicia, a petición de los moriscos de Codo, ordenaron al abad desistir de su empeño de gravar con nuevos impuestos e imponer nuevos derechos a sus vasallos, contravi- 
suales como bolanderas de qualesquiere género, calidad y specie que sean, que a instancia nuestra y de todos nuestros antepassados y del dicho concejo, universidad y singualares personas, vezinos y habitadores del dicho lugar de Codo assí concegil como singular y particularmente o de qualquiere de nossotros y dellos se hayan hecho y obtenido hasta el día presente en qualesquiere días, meses, anyos y lugares y ante y por qualesquiere señores lugarteniente o lugartenientes de dicha Corte dadas, proveydas y despachadas contra los muy illustres y muy reverendos señores abad y monjes y convento de nuestra señora de Rueda, señores nuestros y del dicho lugar siquiere contra sus alcaydes, justicias, officiales y ministros, comissarios, procuradores, arrendadores y personas assí ecclesiásticas como seculares del dicho monasterio o en su nombre que oy son y por tiempo han sido las quales y cada una dellas aquí queremos haver y tenemos por recitadas, expressadas y calendadas" 30 . El documento podía haber sido emitido por cualquier concejo de hombres libres. Y demuestra que los nuevos cristianos no sólo podían acogerse a la protección del Justicia sino que se habían acogido y que éste además había dispensado su protección sin condiciones. El cristiano nuevo, el morisco renegado y enemigo de la monarquía, según la Inquisición y el Consejo de Estado, es para el Justicia un aragonés más y, por tanto, con todos los derechos y privilegios que los Fueros otorgaban a los hombres libres y de Iglesia de Aragón. Por eso lo defenderá contra sus convecinos o contra sus señores cuando éstos amenacen sus derechos. Desgraciadamente nada podrá hacer cuando la Inquisición ande de por medio pero tampoco en esto hay discriminación. Ni el Justicia ni la Diputación pudieron defender a los viejos cristianos ni al propio reino de los abusos inquisitoriales.

Para la monarquía y la Inquisición, los nuevos bautizados de moros eran renegados y traidores, moriscos, y como tales fueron tratados y expulsados. Pero ni el Santo Tribunal ni el Consejo de Estado ni sus corifeos tienen el monopolio de la verdad ni agotan la realidad. La otra documentación, la que no está metida en asuntos de religión ni en razones de estado, ni acusa ni discrimina al recientemente bautizado. En ocasiones ni siquiera lo identifica, y cuando lo hace, lo muestra como nuevo cristiano, es decir, de camino hacia su total integración en la sociedad cristiana y, por tanto, progresivamente alejado de su vieja condición musulmana. Y esta realidad parece al menos tan creíble como la ofrecida por el aparato del Estado. ¿Cómo era realmente la minoría de cristianos nuevos de Aragón?

niendo los pactos y concordias que establecidos en el pasado regulaban las relaciones entre las partes. Para más información sobre la Firma y la Manifestación puede acudirse a: FAIREN GuIllên, V., Antecedentes aragoneses de los juicios de amparo, México, Universidad Autónoma, 1971, pp. 65-105. BONET NAVARRo, A., Procesos ante el Justicia de Aragón, Zaragoza, Guara Editorial, 1982, pp. 108-166.

30. AHN, Clero, leg. 8533, lig. 3, n 34 , s.f. 